\title{
MRI signal changes in the liver following multiple transfusions
}

M Durand, MB ChB
Department of Radiology, Grey's Hospital, Nelson R Mandela School of
Medicine, University of KwaZulu-Natal, Pietermaritzburg
J C Abrahams, MB ChB, FCRad Diag (SA)
Kauffman and Partners, Pietermaritzburg

\section{Introduction}

Diffuse signal changes in the liver on magnetic resonance imaging (MRI) often represent a depositional process with a decreased signal when iron or copper is deposited or an increased signal with fatty deposition. ${ }^{1}$ Such findings are often incidental when imaging is done to identify a cause for other symptoms or to assess for complications of primary pathology.

\section{Case report}

A 68-year-old man presented to our hospital with myelodysplasia, a pre-leukaemic haematological disorder characterised by bone marrow malfunction, which leads to cytopenia of one or more cell lines. Due to his recurrent anaemia, he had been transfused with 20 units of blood over a 4-month period. He was referred to Radiology for MRI of his liver to rule out malignant lesions. At the time of the scan, he had a ferritin level of $951 \mathrm{ng} / \mathrm{ml}$ (normal $20-100 \mathrm{ng} / \mathrm{ml}$ ).

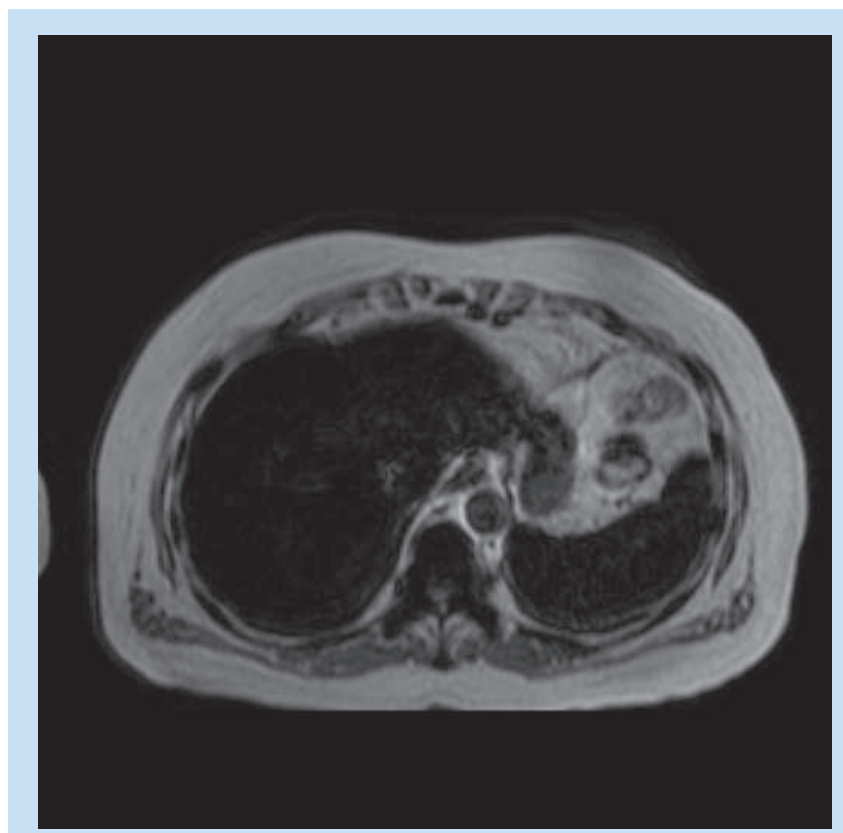

Fig. 1a. Axial T1W images demonstrating decreased signal in the liver and spleen.

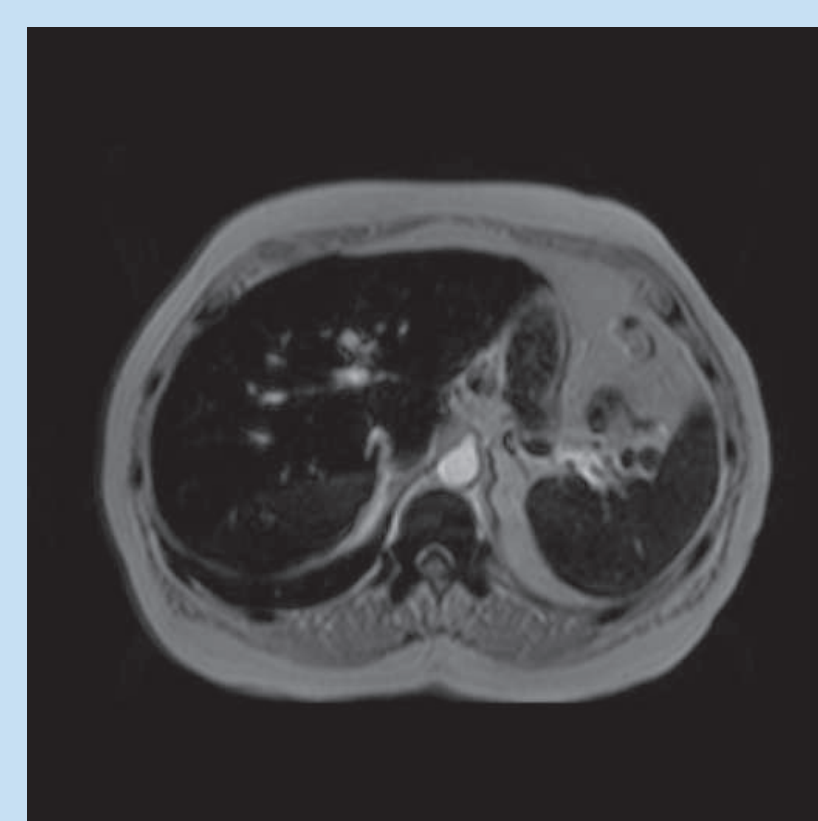

Fig. 1b. Axial T2W image demonstrating T2 shortening in the liver and spleen.

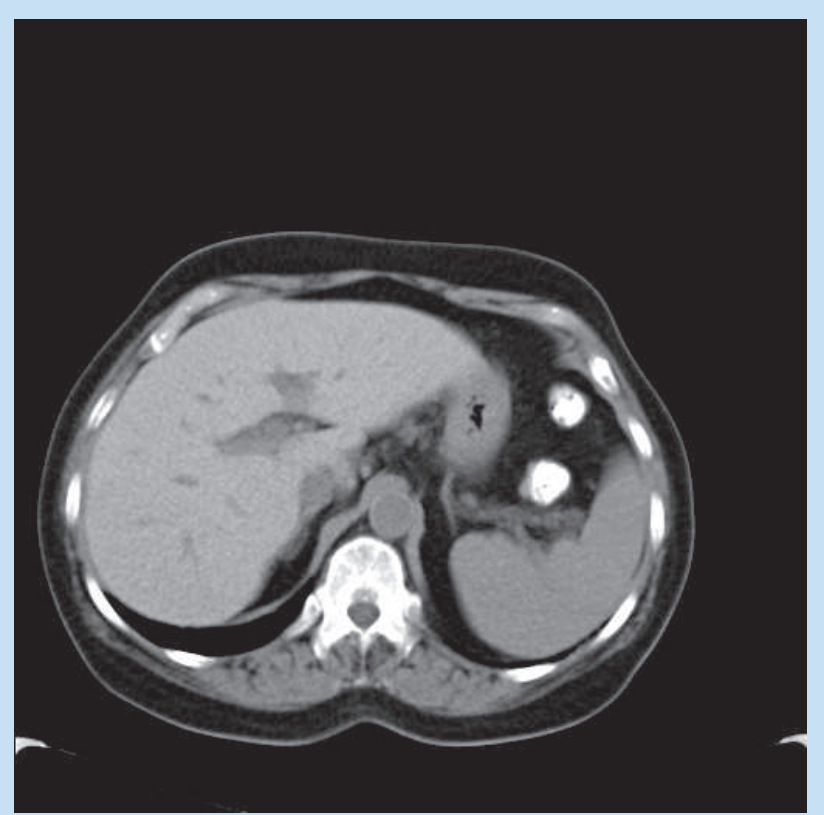

Fig. 2. Unenhanced CT scan of the liver showing a hyperdense liver with an HU of 103 (normal value $54-60^{1}$ ), with normal density of the spleen. 


\section{Discussion}

In patients who receive multiple blood transfusions, the excess iron is initially deposited in the reticuloendothelial system of the liver, spleen and bone marrow as well as in the heart and endocrine system. ${ }^{2}$ This may eventually lead to complications such as transfusion haemosiderosis of the liver, cardiac failure, diabetes and inadequate hypothalamic-pituitary adrenal reserve. The iron that accumulates in the liver is paramagnetic and interacts with adjacent hydrogen nuclei to cause susceptibilityinduced relaxation owing to shortened proton relaxation times. ${ }^{3}$ This leads to decreased signal intensity of the liver on T1W, T2W and STIR images $^{4}$ (as shown in Figs 1a and $1 \mathrm{~b}$ ). The increase in the 1/T2 relaxation rate of the liver is linearly related to the amount of blood transfused up to a level of 60 units, after which no significant increase is seen. ${ }^{5}$ The T2 relaxation rate of the spleen also changes after blood transfusion but is not related to the number of blood transfusions. ${ }^{4}$ Bone marrow may show hypo-intensity secondary to iron deposition after transfusion. No relationship has been demonstrated between bone marrow T2 relaxation rates and serum ferritin levels, or between liver and spleen $1 / \mathrm{T} 2$ relaxation. ${ }^{6}$ Iron deposition may be seen as increased density in the liver and spleen on CT, but is less readily quantifiable (Fig. 2).

\section{Conclusion}

Multiple transfusions result in iron deposits in the reticuloendothelial system, heart and endocrine system. Awareness of the signal changes when incidentally identifying this will avoid misdiagnoses. In addition, T2W MRI can be used as a prognostic tool to quantitatively determine true iron levels in the liver.

1. Grainger RG. Grainger \& Allison's Diagnostic Radiology: A Textbook of Medical Imaging. 4th ed. London: Churchill Livingstone, 2001: 1242.

2. Schafer AI, Cheron RG, Dluhy R, et al. Clinical consequences of acquired transfusional iron overload in adults. N Engl J Med 1981; 304(6): 319-324.

3. Brittenham GM, Badman DG. Noninvasive measurement of iron: report of an NIDDK workshop. Blood 2003; 101(1): 15-19.

4. Bondestam S, Lamminen A, Anttila VJ, Ruutu T, Ruutu P. Magnetic resonance imaging of transfusional hepatic iron overload. Br J Radiol 1994; 67(796): 339-341.

5. Salo S, Alanen A, Leino R, Bondestam S, Komu M. The effect of haemosiderosis and blood transfusions on the T2 relaxation time and 1/T2 relaxation rate of liver tissue. Br J Radiol 2002; 75(889): 24-27.

6. Johnston DL, Rice L, Vick GW 3rd, Hedrick TD, Rokey R. Assessment of tissue iron overload by nuclear magnetic resonance imaging. Am J Med 1989; 87(1): 40-47.

\section{Radiology Positions Canada}

RADIOLOGIST: SK Radiology Associates of Regina is seeking Radiologists to join 16 member sole practice in Regina. RAR serves two acute care hospitals, its two clinics as well as numerous outside clinics and rural hospitals. Canadian Royal College certification or eligibility to write exam preferred. Locum positions are also available. Regina has a booming economy, no traffic and an international airport.

Contact Larry Kliman, Business Manager tel: 306-529-3305 or

$$
\text { e-mail larry@rarsk.com }
$$

